its separate sections, of religion, mythology, philosophy and the various sciences. A large section is devoted to the artistic tradition, both in the theatre and in the plastic arts. A similar division covers speech and music. Rather more than a third of the whole treats of the classical tradition, as it was displayed in particular epochs and regions. Thus both the Hellenistic West and Hellenistic Judaism are fully dealt with, and one passes through the transformations of Byzantium and the Middle Ages, down to the more fragmentary and slighter treatment accorded to the humanism of the present. On this last section the amount of the material available to the editors and their staff of critics was clearly not sufficient to allow the picture presented to be in any way adequate to the facts. But for all the earlier portions, and for the literary and artistic criticism of classical works of all kinds, published quite recently, the catalogue is a gold-mine. One finds here an account of books often not otherwise known at all in England, and the short summary and criticism appended are always expert, sufficient and enlightening. One short and interesting example (of the hundreds which the book contains) may be given :

"Nogara Bartolomeo. The Laocoon group in the Vatican.

"A summary history of the group since its discovery. Different attempts at restoration are described. ... Interesting proof arises from Titian's travesty in his 'Apes-Laocoon', that the chief figure had his arm bent towards his head."

In recommending the whole undertaking, one would only repeat the hope that in the development of the work of the Warburg Institute in London, larger and larger attention may be given to the history of science. On art it is already ample and admirable.

\title{
Mechanisation in Industry
}

\section{Mechanisation in Industry}

By Harry Jerome. (Publications of the National Bureau of Economic Research, Inc., No. 27.) Pp. xxxi+484. (New York: National Bureau of Economic Research, Inc., 1935.) 15s. net.

$\mathrm{T}$ HE habit of producing goods whether they are needed or not, of applying power whether it is effective or not, of utilising inventions whether they are useful or not, pervades almost every department of our present civilisation. The untoward consequences of this materialistic habit, as seen for example in employment, have led to increasing attention being given to the social consequences of mechanisation in recent years. We are at last coming to realise that social inefficiency may be too high a price to pay for mechanical efficiency and that, from the point of view of the community as a whole, industrial efficiency must take account of the effects on the worker and the community as well as of the purely mechanical or chemical efficiency of its processes.

Although the social and cultural aspects of mechanisation have received a certain amount of attention, there has as yet been no detailed account of the process of mechanisation in a broad economic setting, interpreting the details in regard to mechanisation as a whole and to related processes of economic life. Some such account Dr. Jerome attempts to give us in the present study, particu. larly in relation to the nature and significance of current changes in the degree of mechanisation. $\mathrm{He}$ emphasises the wide range of consequences which must be traced if we are to measure accurately the effects of a mechanical change, and his careful technique of treatment should supply a further corrective to hasty or ill-founded assumptions regarding the effects of mechanisation.

In the first instance, Dr. Jerome distinguishes between changes which increase the units of output per hour of labour and those which reduce the number of workers required. $\mathrm{He}$ also directs attention to the effects which may be produced not merely on labour operating a process but also on auxiliary labour such as that required in maintenance, or on embodied labour such as that required in the production of the machine or the power or other services required for its operation, as well as on indirectly required labour like that engaged in transport, selling or advertising. It is only as the effects in all these directions are visualised that we can compute the true effect of a technical change on the community, and attain such an understanding of current changes that the manner and rapidity with which they occur can be in some degree controlled.

Dr. Jerome suggests that the most important single question about current changes in mechanisation is the rate at which they occur. The evidence presented, drawn from a wide range of manufacturing industries as well as from agriculture, mining, building, transport and handling of 
materials, etc., leads him to conclude that a continuing increase in mechanisation at a moderate pace may be expected. Though there are still many possibilities for the extension of mechanisa. tion, there are sufficient obstacles to mechanisation to render uncontrollably rapid mechanisation unlikely. On the contrary, stabilising factors which limit the rate of mechanisation also suggest that the rate of change in mechanisation is relatively stable. Even within the limited range of fluctuations in the rate of mechanisation, the experience of the last ten or fifteen years indicates ill effects which deserve consideration and, moreover, are not beyond reasonable possibility of prediction and control. For example, rapid mechanisation brings a substantial amount of displacement of skill and technological unemployment which, even when the change represents a net gain to society as a whole, may bring serious losses to individual workers, particularly to the older and more highly skilled. Moreover, there is reason to believe that, while advancing mechanisation probably tends to lessen seasonal fluctuations in industry, it may aggravate cyclical fluctuations.

The evidence upon which these conclusions are based is admirably presented, and is supported by statistical data which give the book real value as a work of reference upon the rate of mechanisation of industry. The book is eminently readable, and, while limiting himself closely to the special aspects of mechanisation indicated above, Dr. Jerome indicates a number of directions in which further investigation is required. The challenge to research thus thrown down by problems of obsolescence and plant occupation, the effects of mechanisation upon labour turnover, etc., is not the least of the claims of this book upon the attention of the scientific worker.

R. Brightman.

\section{Witchcraft and Psychopathology}

The Medical Man and the Witch during the Renaissance

By Dr. Gregory Zilboorg. (The Hideyo Noguchi Lectures.) (Publications of the Institute of the History of Medicine, the Johns Hopkins University, Third Series, Vol. 2.) Pp. $x+215+5$ plates. (Baltimore, Md. : The Johns Hopkins Press ; London: Oxford University Press, 1935.) 11s. 6d. net.

WITCHCRAFT and the witchcraft persecutions were a manifestation of the hysteria endemic among the European populations of the Middle Ages; and after the Renaissance, even when the flame of seventeenth century fanaticism, which made a belief in witchcraft a test of orthodoxy, had died down, sporadic outbursts of popular excitement still showed that the evil had not been completely allayed.

In these three lectures Dr. Zilboorg, skilled psychiatrist and trained sociologist, examines the records of the fifteenth and sixteenth centuries with the purpose of demonstrating why, while other branches of medical sciences at the time of the Renaissance entered upon a period of rapid growth with the introduction of the scientific spirit and scientific method, the true nature of the phenomena of witchcraft and demonic possession was only tardily recognised as due to an abnormal psychic state-and that merely by the few. The study of psychopathology and psychiatry made no advance between the middle of the sixteenth century and the end of the nineteenth century.

In the "Malleus Maleficarum", the guide to theory and practice of the medieval inquisitor and witch-finder, there is, Dr. Zilboorg shows, a complete clinical record of psychic abnormalities known to modern science. He also shows by an analysis of records of the examination of cases of demonic possession and of the writings of such authorities as Pare, Paracelsus and Cornelius Agrippa, that medical men 'shied away' from a province expressly, and often explicitly, debarred from the healing art and consigned to the Church and the Law, either as heretical and criminal-the witch ; or as spiritual--the demonically possessed.

Glimmerings of the truth are to be observed among the more advanced masters of medicine, as, for example, in the writings of Paracelsus and Agrippa; but as Dr. Zilboorg shows by copious quotation, the introduction of a scientific attitude of mind and of accurate clinical observation of cases in this field is due to Johann Weyer (1515 or 1516-88), native of Brabant and physician to Wilhelm, Grand Duke of Trier. Weyer was the founder of psychiatry. Unfortunately, Weyer's work became inextricably entangled in the conflicts between heresy and orthodoxy and the Roman and the reformed Churches. Hence, notwithstanding the decay of the active belief in witchcraft, the field of psychopathology continued to be dominated by the theological attitude towards possession for just on three hundred years. 